\title{
Infância Vulnerável e Sucesso na Leitura e Escrita: histórias possíveis
}

\author{
Maria Isabel Donnabella Magrin' \\ Sérgio Antonio da Silva Leite \\ 'Universidade Estadual de Campinas (UNICAMP), Campinas/SP - Brasil
}

RESUMO - Infância Vulnerável e Sucesso na Leitura e Escrita: histórias possíveis. $\mathrm{O}$ artigo foi construído a partir de pesquisa com quatro sujeitos adultos, leitores e produtores de texto, que tiveram uma infância vulnerável. O objetivo foi descrever e analisar as condições que lhes possibilitaram obterem sucesso em seu processo de alfabetização e se envolverem com práticas sociais de leitura e escrita. As verbalizações foram organizadas em núcleos temáticos, a partir dos quais se reconstruíram as histórias de cada um. Observou-se que todos relataram histórias muito significativas na área da leitura durante a infância. No artigo, as análises são representadas pela história de um dos quatro sujeitos e os dados são analisados a partir da abordagem histórico-cultural.

Palavras-chave: Leitura. Escrita. Infância Vulnerável. Mediação. Afetividade.

ABSTRACT - Vulnerable Childhood and Success in Reading and Writing: individual positive examples. This article was built from a research with four adult readers and text producers who had a vulnerable childhood. The aim was to describe and analyze the conditions that allowed them to succeed in their literacy process and engage with the social practices of reading and writing. The verbalizations were organized into thematic units, from which the stories of each one were reconstructed. It was observed that all of them reported very significant stories referring to reading during their childhood. The analyses are represented in the paper by the story of one of the four subjects. Data is analyzed by historical-cultural approach.

Keywords: Reading. Writing. Vulnerable Childhood. Mediation. Affection.

Educação \& Realidade, Porto Alegre, v. 39, n. 3, p. 871-886, jul./set. 2014

Disponível em: <http://www.ufrgs.br/edu_realidade> 
Infância Vulnerável e Sucesso na Leitura e Escrita

\section{Introdução}

A pesquisa teve como objetivo descrever e analisar histórias de sujeitos que tiveram uma infância vulnerável e se constituíram como adultos leitores e produtores de textos autônomos. A análise ocorreu através de dados coletados por entrevistas com adultos que relataram suas vivências e suas experiências com a leitura e a escrita, especialmente durante a infância. A observação pautou-se, principalmente, nas relações dos sujeitos com pessoas próximas, pois, é a partir das relações sociais, através do outro, que o homem transforma-se de sujeito biológico em sujeito sócio-histórico (Vygotsky, 1987; 2007).

Portanto, considera-se o sujeito histórico e social e, assim, acredita-se que deva ser analisado em sua condição concreta de vida. De acordo com o referido autor, "O caminho do objeto até a criança e desta até o objeto passa através de outra pessoa. Essa estrutura complexa é o produto de um processo de desenvolvimento profundamente enraizado nas ligações entre história individual e história social” (Vygotsky, 2007, p. 20).

Ou seja, como sujeito do conhecimento, o homem não tem acesso direto aos objetos, mas acesso mediado, através de recortes do real operados pelos sistemas simbólicos de que dispõe. O autor enfatiza a construção do conhecimento como um processo de interação mediada por várias relações. O conhecimento não está sendo visto apenas como uma ação do sujeito sobre a realidade, mas, também, pela mediação ou interação feita por outros sujeitos. "Nesse sentido, Vygotsky destaca a importância do outro, não só no processo de construção do conhecimento, mas de constituição do próprio sujeito e suas formas de agir" (Tassoni, 2000, p. 1).

Para alguns pesquisadores (Leite, 2003; 2006; Grotta, 2003; Tassoni, 2003), a mediação que se estabelece entre sujeito e objeto do conhecimento é, também, de natureza afetiva e depende, em grande parte, da história e da qualidade da mediação desenvolvida pelos agentes culturais, entre os quais se destacam a família e a escola. Dados de pesquisas, entre elas a de Grotta (2003), sugerem que o processo de constituição dos sujeitos como leitores autônomos tinha forte relação com uma história de vida marcada por essas experiências de mediação essencialmente afetivas, além, é claro, das dimensões cognitivas envolvidas no processo.

As histórias dos adultos investigados possibilitaram identificar inúmeros eventos de mediação que deixaram marcas positivas na relação entre cada sujeito e a escrita. Os quatro sujeitos tiveram pessoas significativas - especialmente na família e na escola - que lidavam de modo peculiar com a leitura e com a escrita, o que, de acordo com a teoria, foi determinante para o fato de os quatro, hoje adultos, gostarem de ler, escrever, utilizando-se da leitura e da escrita em seu dia a dia, indicando que o processo de desenvolvimento estará sempre associado 
a interações sociais, envolvendo sempre conteúdos afetivos - positivos ou negativos - que marcarão a natureza das relações que o sujeito estabelecerá com os objetos culturais. Logo, quando exercidas por pessoas significativas para o sujeito, essas mediações tendem a repercutir de maneira ainda mais intensa.

Leite (2010) destaca que a afetividade relaciona-se com o processo de mediação pedagógica, independentemente do tipo de conteúdo curricular em questão. Menciona também que essas mediações extrapolam os limites da escola: "[...] entretanto, posso supor que quanto mais limitado for o ambiente cultural de uma criança, maior será o efeito das experiências vividas na escola" (Leite, 2010, p. 49).

Nesse sentido, se o professor e a escola compreenderem o aluno como tendo "[...] um papel psicológico marcadamente ativo, ou seja, à medida que vivencia experiências psicológicas, elabora e vivencia ideias, hipóteses e sentimentos, podendo até desenvolver habilidade de análise dessas próprias repercussões subjetivas" (Leite; Tassoni, 2007, p. 120), e assumirem assim, uma postura favorável a uma perspectiva crítica, estarão incluindo-o em um processo de reflexão no qual todos poderão se constituir como sujeitos ativos e conscientes de suas práticas.

Paulo Freire foi um dos primeiros a enfatizar o caráter revolucionário que a leitura e a escrita podem desempenhar. O autor (1980; 1989; 1996) defende que para alcançar a consciência crítica, que possibilita ao homem ser sujeito ativo de sua história e da história da humanidade, a educação deve instigar o aluno a uma reflexão crítica, centrada no diálogo e na troca de experiências entre todos os envolvidos no processo de ensino e aprendizado. Alfabetização, aqui, não se traduz no domínio do código, mas é fazer com os alunos se conscientizem e se sintam sujeitos pertencentes à história. O papel da alfabetização é o de contribuir para o desenvolvimento de uma consciência crítica, ampliar a capacidade dos alunos de se relacionarem e compreenderem o mundo político-social em que vivem, para que se sintam capazes de participar ativamente nas mudanças que julgarem necessárias.

Ao se relacionar a alfabetização à experiência social que a precede, é possível defender as concepções atuais de alfabetização que afirmam que, embora a alfabetização e o letramento sejam processos distintos, podem e devem ser articulados para que se ensine a ler e a escrever a partir do contexto das práticas sociais, para tornar o indivíduo, simultaneamente, alfabetizado (domínio do código escrito) e letrado (uso social da escrita). De acordo com Nucci (2003), o sucesso do desempenho escolar pode ser determinado pelo uso da escrita em diversas funções do cotidiano. Soares (2004) caracteriza esse processo - de ensinar a ler e a escrever no contexto das práticas sociais de leitura e de escrita - como alfabetizar letrando. Afirma também que, quando a criança aprende a dominar o código escrito de maneira contextualizada, a aprendizagem torna-se mais prazerosa, pois ocorre de maneira mais significativa.

Educação \& Realidade, Porto Alegre, v. 39, n. 3, p. 871-886, jul./set. 2014

Disponível em: <http://www.ufrgs.br/edu_realidade> 
Infância Vulnerável e Sucesso na Leitura e Escrita

Dessa maneira, a qualidade das mediações vai se constituir como um importante determinante das concepções elaboradas pela criança sobre a escrita.

No caso presente, pressupõe-se que o fato de, mesmo em condições adversas, os sujeitos terem aprendido a ler e a escrever e se constituído como leitores bem sucedidos, só foi possível graças a mediações positivas exercidas por pessoas significativas e de grande valor afetivo para eles. Assim, pensou-se em buscar e analisar sujeitos que tiveram uma infância vulnerável e que se constituíram como adultos leitores e produtores de texto, especialmente em seu ambiente de trabalho. Quais seriam os principais mediadores que os teriam levado a esse sucesso? Como isso teria ocorrido em suas vidas?

\section{A Pesquisa}

De acordo com a abordagem histórico-cultural (Vygostky, 1987; 2007) o que determina - em grande parte - as condições de aprendizagem e de vulnerabilidade do sujeito é o seu meio social, visto que o sujeito se constrói na e pela interação humana, em situações concretas de vida. O sujeito, ser histórico e social, é marcado pela cultura na qual está inserido e passa a interagir - desde o seu nascimento - com o mundo real em que vive e com as formas de organização desse real.

Na abordagem teórica aqui assumida, supõe-se claramente que o sujeito está sempre em transformação e que a vulnerabilidade nada mais é do que a situação em que ele se encontra naquele determinado momento. Ou seja, considera-se que é a partir do outro que a vulnerabilidade se estabelece em determinado meio, e é absolutamente possível superá-la como sujeito. De acordo com apontamentos de Sierra e Mesquita (2006), a qualidade dos relacionamentos é um dos determinantes para a superação dessa condição. É assim no caso da aprendizagem da leitura e da escrita, temas centrais nesta pesquisa.

Também se faz necessário explicitar que o letramento, sob a óptica da abordagem histórico-cultural, é uma importante condição para o indivíduo se tornar um cidadão crítico e consciente, e pode ser analisado entendendo a escrita como um sistema simbólico, de natureza histórica e social. Pode-se pressupor que o letramento pode possibilitar novas formas de inserção cultural, criando condições para o indivíduo viver situações diferenciadas utilizando a escrita em seu cotidiano.

Acredita-se que, assim como o contexto social determina as práticas sociais do indivíduo, também são necessárias habilidades individuais de leitura e escrita, considerando-se que o letramento está relacionado com aspectos individuais e sociais. De acordo com Soares (1998), o que muda no indivíduo que adquire um bom nível de letramento é o seu lugar social. Esse indivíduo, diferentemente daquele que apenas adquiriu o código escrito, está melhor instrumentalizado para compreender e participar ativamente da sociedade na qual está inserido. 
A pesquisa (Magrin, 2012) a respeito da qual discorre este texto apresenta uma abordagem qualitativa, com base em Ludke e André (1986) e Bogdan e Biklen (1982), uma vez que analisou histórias de alfabetização, com o objetivo de compreender como sujeitos, apesar de terem vivido uma infância vulnerável, conseguiram se tornar bons leitores e profissionais de sucesso.

Optou-se, pelo procedimento das entrevistas recorrentes que, de acordo com Simão (apud Leite; Colombo, 2006), pode ser caracterizado como um processo interativo entre pesquisador e sujeito, visto que um dos atores pretende conhecer o processo pelo qual o outro se constitui - é o sujeito pesquisado quem detém a experiência. Larocca (1996, p. 32) define como "[...] uma espécie de interação social planejada”.

Os sujeitos que participaram da referida pesquisa foram escolhidos intencionalmente através de uma entrevista semiestruturada, cujo objetivo era identificar quais indivíduos adequavam-se ao perfil estabelecido: pessoas que tiveram uma infância considerada vulnerável, mas que se constituíram como adultos leitores e produtores de textos. Portanto, essa entrevista foi composta por dois temas: a infância vulnerável e o sucesso na alfabetização. As falas foram gravadas em áudio, transcritas e analisadas. Após a análise, optou-se em incluir os quatro sujeitos que foram entrevistados, visto que todos eles se enquadraram nos critérios. Para o presente artigo foi escolhido um dos quatro sujeitos, apesar de todos eles apontarem para discussões e resultados semelhantes.

\section{A História de Ana}

Ana, viúva, 67 anos, trabalhou na mesma escola que a pesquisadora, que já havia ouvido falar sobre sua história de vida. Negra, filha de lavradores, passou toda a sua infância e juventude no vale do Paranapanema, em casas feitas de pau a pique e reboco, cobertas de sape. Lá viviam ela, seu pai, sua mãe e seus onze irmãos. As camas onde dormiam eram feitas de tarimbas, ou seja, era composta por quatro forquilhas de uma árvore chamada bicheira, fincadas ao chão e coberta de palha. Não havia segurança e na casa entravam vários tipos de animais e insetos. Embora não chovesse dentro da residência, no inverno Ana passava muito frio, não tinha agasalho, sapato ou cobertor para se esquentar. Não possuía residência fixa. $\mathrm{O}$ trabalho de seu pai era derrubar a mata, plantar café e, quando o café estivesse dando a primeira colheita, o dono do terreno ficava com as terras, e a família partia em busca de um novo serviço. Não havia luz elétrica, nem água encanada. Os vizinhos distavam aproximadamente quinhentos metros uns dos outros. $\mathrm{O}$ transporte utilizado era uma carroça que ficava com o pai, implicando que o restante da família andasse sempre a pé. A alimentação era de subsistência: comia-se o que se cultivava.

Educação \& Realidade, Porto Alegre, v. 39, n. 3, p. 871-886, jul./set. 2014.

Disponível em: <http://www.ufrgs.br/edu_realidade> 
Para poder frequentar a escola, Ana e seus irmãos saiam de madrugada, no escuro, e caminhavam cerca de oito quilômetros. A única escola da região era grande, feita de madeira, e Ana a considerava muito boa, embora se lembre da dificuldade em adquirir o material escolar. Desde os seis anos de idade, Ana trabalhava fazendo pequenos serviços em casa: cozinhando, cuidando dos irmãos, trazendo água... Não conhecia o que era lazer, nem aos finais de semana.

Com oito anos já tinha problema de tireoide e anemia. Acredita que seu estado de saúde era frágil pelo esforço físico diário, e por não ter merenda ou alimentação adequada. $\mathrm{O}$ acesso ao sistema de saúde era limitado. Tanto que seu problema foi descoberto apenas na escola, e era lá que Ana dava continuidade ao tratamento. Assim como ela, seus irmãos também enfrentavam sérios problemas de saúde. O mais velho teve uma alergia muito forte - que Ana pensa ter sido relacionada ao inseto barbeiro - e faleceu, aos vinte e quatro anos de idade.

Ana precisou sair da escola aos onze anos, para ajudar seu pai na lavoura e, com sua isso, os sintomas voltaram. Com dezesseis anos, entre a vida e a morte, sua tia a levou a São Paulo, onde ficou, por um ano, tratando da tireoide e da anemia que, segundo ela, evoluía para leucemia. Mesmo retornando à zona rural, não podia mais exercer o trabalho pesado e, por conta disso, estava sem trabalhar. É a partir desse momento que a história de Ana começa a mudar.

Mesmo sem ter formação, Ana começou a trabalhar como professora, a pedido do prefeito da pequena cidade onde morava. Com muito esforço e dedicação, conseguiu terminar o Magistério. Aos cinquenta e oito anos de idade, realizou seu sonho: passou no vestibular de uma Universidade particular da cidade de Campinas, e, aos sessenta e um anos de idade, formou-se Pedagoga. Hoje, Ana é professora aposentada do Estado de São Paulo e professora ativa da Prefeitura de Campinas. Por conta de sua profissão, utiliza-se diariamente da leitura e da escrita. Em casa, lê muitos livros, revistas e jornais. Considera que entende muito bem o que lê e gosta muito de estar em contato com a leitura e com a escrita.

\section{O Improvável é Possível - indo além das primeiras impressões}

As condições precárias em que Ana viveu durante sua infância e juventude devem ser consideradas, porém, o que se observa é que, apesar de todas as suas dificuldades e limitações, ela encontrou pessoas que exerceram mediações positivas entre ela e o mundo dos textos escritos. Observa-se claramente que, a partir dessas mediações, ela foi se constituindo em contato com a leitura e a escrita. Mais que isso: se tornou uma profissional que lida diariamente com textos escritos; uma professora de sucesso.

876 Educação \& Realidade, Porto Alegre, v. 39, n. 3, p. 871-886, jul./set. 2014 Disponível em: <http://www.ufrgs.br/edu_realidade> 
Em primeiro lugar, durante toda a sua infância, nota-se a forte presença da mãe como mediadora na relação de Ana com a leitura e com a escola. Durante toda sua fala nas entrevistas, expressou o carinho, o amor e a admiração que sempre teve por ela, afirmando que fora a maior mestra de sua vida. E todo esse sentimento esteve muito ligado à relação de Ana com o mundo da leitura e da escrita.

Sua mãe tinha quatro livros bem grossos, guardados no fundo do baú, que foram trazidos por uma tia, que morava em São Paulo. Três deles eram de histórias, e a mãe gostava muito de lê-los para seus filhos. Apesar de não escrever nem o nome, lia muito bem. Ana e suas irmãs chegavam a decorar as histórias que, segundo Ana, eram muito sugestivas. Diz que sua mãe tinha uma maneira especial de contar histórias, e a considera uma grande educadora. E conta também que a leitura fazia parte da rotina da família. Quando sua mãe chegava da roça, onde ela trabalhava a maior parte do tempo, das nove às cinco da tarde, todos tomavam banho e iam ouvir as suas histórias: "[...] era um prazer ficar nós, pequenos, em volta da minha mãe ouvindo história”.

Ana diz que, para a sua mãe, o livro era como um tesouro e que, após lê-los, os guardava com cuidado. Além dos livros, sua tia, quando vinha visitar a família na roça, trazia exemplares de uma revista, chamada Cruzeiro, que na casa de Ana também eram relíquias e duravam anos.

Outro material, a que a família de Ana tinha acesso, era o jornal usado que sua mãe trazia para forrar as paredes que eram feitas de taipa. Foi em um deles que Ana leu suas primeiras palavras: "Diário do Estado de São Paulo".

Ela narra sua alegria: “[...] para mim foi assim uma maravilha, porque eu já sabia o que estava rabiscado ali!”.

Ana acredita que, pelo desejo que a mãe teve em aprender e não conseguir frequentar uma escola, ela se esforçava para que os filhos pudessem saber mais que ela. Fazia de tudo para que sempre pudessem frequentar as aulas, inclusive, confeccionava com sacos de açúcar, o uniforme dos filhos.

Ana também contou com um tio, de quem gosta muito e que era responsável por dialogar com seu pai, que era contra os estudos para as filhas mulheres. Esse tio a motivava a continuar na escola, dando-lhe conselhos, incentivos e levando lanche para ela todos os dias.

Com relação à escola, Ana sente que não foi acolhida como deveria. Conta que a maioria dos professores cobrava dos alunos disciplina e rigidez de maneira excessiva. Mas outros eram pacientes e ofereciam-lhe atenção e carinho. Com o passar dos anos, apesar das dificuldades que enfrentou, sempre havia alguém incentivando-a e apoiando-a para persistir nos estudos, especialmente professores e amigos, até que ela conseguisse se formar: primeiro no colegial, depois no magistério e, anos mais tarde, em Pedagogia.

Educação \& Realidade, Porto Alegre, v. 39, n. 3, p. 871-886, jul./set. 2014.

Disponível em: <http://www.ufrgs.br/edu_realidade> 
Durante toda a história que Ana reconta, é possível perceber as relações afetivas que perpassam entre sujeito-objeto-agente mediador. Tassoni (2000) destaca que o que se diz, como se diz, em que momento e por quê, assim como o que se faz, como se faz, em que momento e por quê, afetam profundamente as relações entre sujeito e o objeto do conhecimento.

No caso aqui analisado, bem como nos casos dos outros três sujeitos investigados, essas mediações primeiramente estão concentradas na família. É lá onde aconteceram as primeiras e as mais marcantes interações durante a infância dos sujeitos. Além disso, na família essas interações foram exercidas de maneira intensa e especialmente afetivas.

Segundo Souza (2006), com relação aos membros da família,

Por serem tão próximos e ativos na vida das crianças, esses personagens, em nosso meio, têm um papel extremamente importante, uma vez que serão eles os agentes que possibilitarão à criança vincular-se com a cultura...., constituir sua visão de mundo e apropriar-se das práticas culturais que manterá durante sua vida (Souza, 2006, p. 230).

No presente artigo, entende-se família como “[...] um pequeno grupo social composto por indivíduos relacionados uns aos outros em razão de fortes lealdades e afetos recíprocos, ocupando um lar ou um conjunto de lares que persiste por anos e décadas" (Macedo, 1994, p. 185).

De acordo com os autores, as finalidades da família consistem em permitir a sobrevivência e o desenvolvimento de seus membros, procurando atender as necessidades de todos. As ligações entre os envolvidos são extremamente fortes, independentemente de como sejam estabelecidas. Por serem fortes, as mediações realizadas nesse contexto são extremamente significativas e, portanto, importantes para o aprendizado e o desenvolvimento do sujeito.

Souza (2006, p. 230) afirma que “[...] quando discutimos a infância e as experiências que ocorrem nessa fase, é fundamental situar o papel da família, uma vez que, quando pequenos, o contato com outras pessoas concentra-se no ambiente familiar".

Retomando os dados da pesquisa citada (Magrin, 2012), no caso de Ana, pôde-se notar que sua mãe exerceu uma mediação bastante positiva com relação ao mundo da leitura. Ana conta que ela proporcionava prazer aos filhos quando lia suas histórias, mesmo que eles já as conhecessem muito bem. As imagens desses momentos ainda se mantêm na memória de Ana. Além da mãe, pode-se dizer que a tia que trazia os livros e jornais também teve influência em formação, bem como seu tio Tadeu, que estava sempre presente e estimulando-a para que não abandonasse os estudos, apesar da posição do pai, que era contra as filhas mulheres estudarem. 
Observa-se, portanto, que assim como na pesquisa de Grotta (2000), as histórias de mediações aparecem antes de os sujeitos estarem regularmente matriculados na escola. De acordo com Oliveira e Rego (2003, p. 23), “[...] o ser humano aprende, por meio do legado de sua cultura e da interação com outros humanos, a agir, a pensar, a falar e também a sentir... Nesse sentido o longo aprendizado sobre emoções e afetos se inicia nas primeiras horas de vida de uma criança e prolonga por toda a sua existência”.

Para Vygotsky (1987), o elo de todo o processo de aprendizagem são os conceitos: os conceitos espontâneos - desenvolvidos no cotidiano e conceitos científicos - desenvolvidos na escola. Enquanto os primeiros desenvolvem-se de forma espontânea a partir do meio social do qual a criança faz parte, os científicos dependem de instrução, portanto, de ações intencionais, dirigidas e programadas. Como explicam Góes e Cruz (2006, p. 35),

Enquanto os conceitos espontâneos são elaborados nas situações de utilização da linguagem, nas relações cotidianas, os científicos tornam-se acessíveis principalmente nas relações escolarizadas, pela mediação deliberada e explícita de um adulto que visa a aquisição pela criança de conceitos sistematizados. Como parte de sistemas explicativos mais amplos, organizados logicamente, os conceitos científicos demandam, em sua elaboração, operações lógica complexas, que ainda não são dominados pela criança.

É importante também mencionar que os conceitos científicos podem, inclusive, afetar os conceitos espontâneos, à medida que a criança começa a pensar sobre eles com sistematicidade e reflexividade. $\mathrm{Na}$ realidade, os dois processos caminham em paralelo, mas em direção opostas, um afetando o outro, durante todo o desenvolvimento. Por isso tanto os conhecimentos obtidos na escola, como os obtido fora dela são de suma importância para um avanço no processo de aprendizagem e de desenvolvimento.

Como pôde-se observar, no caso dos quatro sujeitos da pesquisa de Magrin (2012), assim como a família, a escola também contribuiu de maneira determinante para o estabelecimento do vínculo sujeito x objeto. Em três das quatro histórias, foram lembradas cenas que, de alguma maneira, contribuíram não apenas para o avanço cognitivo dos sujeitos como alunos, mas com o estabelecimento de vínculos afetivos positivos entre esses alunos e os conteúdos escolares, - entre eles a leitura e a escrita. Isso porque o ensino foi desenvolvido em um ambiente afetivamente favorável, através de aulas interessantes e de professores, que de alguma maneira, conseguiram favorecer positivamente essa relação. $\mathrm{O}$ caso de Ana foi uma exceção. Ficou claro, através de suas palavras, que frequentar a escola era uma condição que auxiliava no enfrentamento de sua realidade. Talvez, a escola fosse para ela o único local onde poderia realmente ser tratada como uma criança. E, possivelmente, por con- 
Infância Vulnerável e Sucesso na Leitura e Escrita

ta disso, a escola que a castigava com conteúdos sem sentido, não tenha provocado nela marcas aversivas, afastando-a do mundo da leitura e da escrita. Hoje, adulta e professora, ela é capaz de fazer julgamentos e afirma que tudo o que viveu na escola era um absurdo. Mas, na época, era o modo que tinha de escapar um pouco da vida que levava.

Leite (2010, p. 49) afirma que “[...] quanto mais limitado for o ambiente cultural de uma criança, maior será o efeito das experiências vividas na escola”. Nas histórias dos quatro sujeitos, pode-se observar a ênfase dada por eles ao processo de escolarização e às relações afetivas que se desenvolveram no interior da instituição.

Ana diz que aprendeu a ler e a escrever pelo ensino tradicional, baseado na cartilha e na cópia. Esse processo de ensino propiciou-lhe o domínio do código escrito em pouco tempo de escolarização, mas o acesso a variados tipos de texto, que caracteriza o letramento, vinha acontecendo paralelamente, através de outras práticas ou de membros da família como mães, tios e avós.

Ana considera que gostava da escola porque não conhecia outras coisas além do local onde morava e das poucas coisas que aquele ambiente oferecia, mas conta que sofreu bastante com o ensino tradicional, especialmente pela escola não levar em consideração sua situação de criança pobre e filha de lavradores. Para ela, foi muito difícil o ingresso na escola. Acostumada a trabalhar pesado com ferramentas da agricultura, não tinha coordenação motora para segurar o lápis. No primeiro dia de aula, já deveria escrever seu nome e copiar as palavras da lousa e, se não fizesse, apanhava da professora. Ela diz que não teve outra opção, a não ser se esforçar ao máximo e aprender logo a ler e a escrever. Além disso, não se opunha aos castigos, pois era visto por todos - naquela época - como um direito do professor e cabia ao educando seguir à risca todas as regras e normas impostas. Como Ana queria muito aprender, não se importava e nem refletia sobre o que lhe acontecia e diz que a escola era algo que a fazia sair de sua dura rotina de trabalho na roça; por isso gostava de frequentá-la.

Por outro lado, todos os sujeitos - inclusive Ana - tiveram professores que marcaram positivamente sua relação com o estudo e com o mundo da leitura e da escrita. Relações semelhantes também demonstram as pesquisas relacionadas com o tema Meu professor inesquecível (Tagliaferro, 2003; Falcin, 2003). Tagliaferro (2003; 2006), em sua pesquisa, coletou depoimentos de alunos sobre um professor de uma pequena cidade do interior de São Paulo. Esse professor possuía uma maneira especial de ministrar suas aulas e de se relacionar com seus alunos, tendo sido importante na vida de várias gerações de jovens da cidade. $\mathrm{Na}$ pesquisa, através dos depoimentos, fica evidente o seu papel determinante na formação de seus alunos como leitores e escritores, bem como nota-se que o professor $\mathrm{M}$. modificou a visão de mundo e a maneira de interagir dos seus alunos com a leitura.

880 Educação \& Realidade, Porto Alegre, v. 39, n. 3, p. 871-886, jul./set. 2014 Disponível em: <http://www.ufrgs.br/edu_realidade> 
No caso de Ana, destaca-se igualmente a relação afetiva que teve com alguns de seus professores e a atenção que recebiam dos mesmos. Também elogiam a maneira com que eram ministradas as aulas e o conhecimento que esses professores possuíam. Quase todos os sujeitos mencionaram a disposição e vontade que esses docentes tinham de que todos seus alunos aprendessem, assim como disseram que os conhecimentos transmitidos por eles foram além do previsto no currículo escolar. Geralmente eram professores rigorosos, que dominavam muito bem sua sala e que no cotidiano, iam além de explicações baseadas no currículo escolar; traziam lições de vida.

Ana, apesar de declarar que sofreu com o excesso de rigidez na escola, elogia os esforços oferecidos por alguns professores e o encorajamento que eles lhe passavam. O primeiro professor que lhe traz uma lembrança positiva é Diogo, da segunda série. Ele percebia as necessidades financeiras de Ana e trocava seu lanche - leite gelado, pão com presunto e queijo - pelo dela - batata doce e ovos fritos, preparados pela mãe. Além disso, ele não media esforços para ajudá-la demonstrando muito interesse por sua aprendizagem. Como Ana enfrentou muitos contratempos, entre eles uma forte anemia e problemas na tireoide, bem como gravidez inesperada, sua vida escolar foi várias vezes interrompida. E algumas das pessoas que não a deixaram desistir foram o diretor e professor Jorge, tão querido e admirado por Ana e a professora Carolina, que se apegou muito a ela por perceber sua situação e ofereceu-lhe até apoio material para que persistisse nos estudos. Ambos frequentemente teciam elogios, com palavras de incentivo e de perseverança.

Para considerar o sucesso dos quatro sujeitos como leitores e escritores, também deve-se levar em consideração outras mediações oferecidas a cada um deles, a partir de pessoas próximas e/ou de situações experienciadas. No caso de Ana, a oportunidade de trabalhar na escola oferecida pelo prefeito trouxe-lhe novas perspectivas. Aos vinte e três anos, sem formação e sem poder trabalhar na roça - devido a uma cirurgia -, mas precisando muito trabalhar, aceitou dar aulas em uma pequena escola rural, próxima de sua casa. O que ensinava aos alunos era exatamente o que havia aprendido durante os quatro anos em que se manteve matriculada como aluna em uma escola - foi o início de sua longa carreira docente.

Em todos os casos, os sujeitos sempre consideraram o estudo, a leitura e a escrita como objetivos importantes de serem alcançados. Isso, possivelmente, se deva ao fato de que as pessoas significativas de seu meio social valorizavam a educação e entendiam o estudo, a leitura e a escrita como sendo fundamentais para que o sujeito pudesse alcançar uma mudança positiva em suas vidas. Isso pode ser observado em alguns momentos de suas histórias: Ana afirma que, por não ter tido estudo, sua mãe e sua família viam a leitura e a escrita como uma “[...] luz que começava a brilhar, uma dádiva”. Sua mãe e seu tio ofereciam-lhe 
Infância Vulnerável e Sucesso na Leitura e Escrita

todo o incentivo para que sua trajetória escolar não fosse interrompida. Também recebeu o apoio de seus amigos, Clara e Sebastião, e Inês, mãe de sua amiga Cida, que, em diferentes momentos, cederam sua casa, bem como muito carinho, para evitar que Ana tivesse que interromper os estudos. Todos eles admiravam seu esforço e a elogiavam constantemente, queriam vê-la estudando e mudando de vida. Dentro da escola, quando afirmava pensar em desistir, seu professor Jorge e sua professora Carolina a impediam de tomar tal atitude, reforçando sempre a importância do estudo, especialmente para que ela tivesse um bom emprego e pudesse ajudar seus pais. Ofereciam-lhe todo o apoio e motivação que ela necessitava para continuar.

Além de familiares e membros das escolas, aparecem as figuras de amigos que, de uma maneira ou de outra, contribuíram de uma maneira positiva na vida dos sujeitos. Ana, como já foi posto, teve os amigos que acreditaram nela e a acolheram em suas casas, a fim de evitar que seus estudos fossem interrompidos. Primeiro, Clara e Sebastião: pobres, boias frias, analfabetos, com filhos pequenos para criar, que a acolheram com muito zelo e amor. Todos os dias, quando chegava cansada, havia em cima do fogão de lenha uma marmita aquecida para ela. Ana acredita que cada um da família deixava de comer um pouco para que sobrasse para seu jantar. No ano seguinte, foi transferida para o município vizinho, e lá pernoitava na casa de outra conhecida: Inês que era muito preocupada com estudos dos filhos, e acreditava que Ana seria uma excelente companhia para sua filha Cida, que, diferente de Ana, não era muito envolvida com os estudos. Inês, então, oferecia a Ana o que ela necessitasse, inclusive material para estudo, pois sem essa ajuda, Ana demoraria meses para comprar.

Os dados sugerem que, mesmo em um ambiente aparentemente desmotivador e diante de uma situação de vulnerabilidade social, é possível aprender a ler e a escrever de maneira prazerosa e com sucesso, se no meio social houver pessoas envolvidas com leitura e com escrita que exerçam essa mediação de maneira afetivamente positiva. Leite (2006) diz que "Podemos afirmar, sem exageros, que a qualidade da mediação vivenciada pelo aluno, em muitos casos, determina toda a história futura da relação entre ele e os diversos conteúdos estudados" (2006, p. 38). Tal citação se refere às mediações ocorridas no interior da escola, mas pode ser ampliada também para outros contextos, como por exemplo, para a família. Por outro lado, uma mediação afetivamente negativa pode ter efeitos desastrosos, como, por exemplo, afastar o sujeito do objeto de ensino.

Nas quatro histórias, observa-se claramente o papel do outro e as relações vivenciadas externamente que repercutiram e possibilitaram a constituição de sujeitos leitores e produtores de texto autônomos. Também se observam conteúdos afetivos - como o carinho, o elogio, a atenção, a preocupação, o prazer, o respeito - que emergiram durante as experiências de leitura, o que, possivelmente, contribuiu para que os 
sujeitos internalizassem e associassem esses conteúdos às práticas de leitura.

De acordo com a abordagem histórico-cultural, o sujeito define seu modo de ser a partir das internalizações dos significados e sentidos constituídos nas relações sociais que estabelece, especialmente com pessoas próximas como familiares, professores e amigos.

Essa abordagem considera que o sujeito é histórico e social, e, portanto, desenvolve-se de acordo com a pertinência cultural e as possibilidades que o meio no qual está inserido oferece. Não se pode ignorar o fato de que o sujeito é ativo nesse processo, e registra cognitiva e afetivamente todas as suas experiências, constituindo-se a partir/com elas.

\section{Conclui-se...}

Enfim, observa-se que a relação afetiva positiva, que os sujeitos estabeleceram com a leitura e a escrita, não ocorreu por acaso, mas resultou de histórias de mediações envolvendo outras pessoas que, certamente, influenciaram na qualidade desses vínculos. Observou-se que, tanto o processo de constituição do sujeito como suas formas de agir - o que inclui o modo como se lê e a relação com a leitura - sofrem influências do outro, e, muitas vezes, os próprios sujeitos têm consciência dessas influências. Tais mediações marcaram o futuro desses indivíduos e tiveram papel decisivo nos seus respectivos processos de constituição como sujeitos leitores e/ou escritores.

Para finalizar, pretende-se abrir caminho para futuras pesquisas e reflexões envolvendo casos de vulnerabilidade social e afetividade, tendo em vista que a dimensão afetiva é crucial no processo de aprendizagem. Os sujeitos pesquisados são casos de sucesso, mas sabe-se que muitas vezes esse sucesso não é alcançado, especialmente em ambientes vulneráveis que não apresentam condições mínimas de saúde, higiene, alimentação, conforto, educação...

É interessante notar que em nenhum dos casos as mediações ocorreram apenas em um ambiente, mas, concomitantemente - na maior parte dos casos - na família e na escola. Uma vez reconhecido o indispensável papel da família na constituição de sujeitos leitores e escritores, é necessário pensar, então, ações que as atinjam, e que as permitam se reconhecerem como detentoras desse importante papel.

A escola, por sua vez, responsável pelo ensino de maneira sistematizada, necessita garantir a todos - especialmente as crianças que vivem em ambientes vulneráveis e que nem sempre contam com as garantias mínimas de direito - uma educação de qualidade e agir em prol desse grande objetivo.

Recebido em 12 de abril de 2013 Aprovado em 22 de agosto de 2013 


\section{Referências}

BOGDAN, Robert; BIKLEN, Sari. Investigação Qualitativa em Educação. Tradução de Maria João Alvarez, Sara Bahia dos Santos e Telmo Mourinho Baptista. Porto Editora, 1982.

COLOMBO, Fabiana Aurora. As Dimensões Afetivas nas Atividades de Ensino em Classes de Alfabetização. In: LEITE, Sérgio Antonio da Silva Leite (Org.). Afetividade e Práticas Pedagógicas. São Paulo: Casa do Psicólogo, 2006. P. 175-193.

FALCIN, Daniela Cavani. Afetividade e Condições de Ensino: a mediação docente e suas implicações na relação sujeito objeto. 2003. 148 f. Monografia (Mestrado em Educação) - Programa de Pós-Graduação da Faculdade de Educação da Unicamp, Campinas, 2003.

FREIRE, Paulo. Conscientização: teoria e prática da libertação - Uma introdução ao pensamento de Paulo Freire. São Paulo, Moraes: 1980.

FREIRE, Paulo. A Importância do Ato de Ler: em três artigos que se completam. 42. ed. São Paulo: Cortez, 1989.

FREIRE, Paulo. Pedagogia da Autonomia: saberes necessários à prática educativa. São Paulo: Paz e Terra, 1996.

GÓES, Maria Cecília Rafael; CRUZ, Maria Nazaré. Sentido, Significado e Conceito: notas sobre as contribuições de Lev Vigotski. Pro-Posições, Campinas, Unicamp, v. 17, p. 31-45, 2006.

GROTTA, Ellen Cristina Baptistella. Processo de Formação do Leitor: relato e análise de quatro histórias de vida. 2000. 268 f. Monografia (Mestrado em Educação) - Programa de Pós-Graduação da Faculdade de Educação da Unicamp, Campinas, 2000.

GROTTA, Ellen Cristina Baptistella. Formação de Leitor: Importância da Mediação do Professor. In: LEITE, Sérgio Antonio da Silva (Org.). Alfabetização e Letramento: contribuições para as práticas pedagógicas. Campinas: Komedi, 2003. P. 129-154.

LAROCCA, Priscila. Conhecimento Psicológico e Séries Iniciais: diretrizes para formação de professores. 1996. 263 f. Monografia (Mestrado em Educação) - Programa de Pós-Graduação da Faculdade de Educação da Unicamp, Campinas, 1996.

LEITE, Sérgio Antonio da Silva Leite. Alfabetização: em defesa da sistematização do trabalho pedagógico. In: ARANTES, Valéria Amorim (Org.). Alfabetização e Letramento: pontos e contrapontos. São Paulo: Summus, 2010. P. 15-74.

LEITE, Sérgio Antonio da Silva. Afetividade e Práticas Pedagógicas. In: LEITE, Sérgio Antonio da Silva (Org.). Afetividade e Práticas Pedagógicas. São Paulo: Casa do Psicólogo, 2006. P. 15-45.

LEITE, Sérgio Antonio da Silva. Notas Sobre o Processo de Alfabetização Escolar. In: LEITE, Sérgio Antonio da Silva (Org.). Alfabetização e Letramento: contribuições para as práticas pedagógicas. Campinas: Komedi, 2003. P. 21-46. LEITE, Sérgio Antonio da Silva; TASSONI, Elvira Cristina Martins. Afetividade e Ensino. In: SILVA, Ezequiel Theodoro da (Org.). Alfabetização no Brasil: questões e provocações da atualidade. Campinas: Autores Associados, 2007. P. 113-137.

LÜDKE, Menga; ANDRÉ, Marli. Pesquisa em Educação: abordagens qualitativas. São Paulo: EPU, 1986. 
MACEDO, Rosa Maria. A Família diante das Dificuldades Escolares dos Filhos. In: OLIVEIRA, Vera Barros; BOSSA Nádia Aparecida (Org.). Avaliação Psicopedagógica da Criança de Zero a Seis Anos. Rio de Janeiro: Editora Vozes, 1994. P. 185-206.

MAGRIN, Maria Isabel Donnabella. Histórias de Envolvimento com a Escrita de Sujeitos que Tiveram uma Infância Vulnerável. 2012. 197 f. Monografia (Mestrado em Educação) - Programa de Pós-Graduação da Faculdade de Educação da Unicamp, Campinas, 2012.

NUCCI, Eliane Porto. Alfabetizar Letrando... Um desafio para o professor! In: LEITE, Sérgio Antonio da Silva (Org.). Alfabetização e Letramento: contribuições para as práticas pedagógicas. Campinas: Komedi, 2003. P. 47-71.

OLIVEIRA, Marta Kohl; REGO, Teresa Cristina. Vygotsky e as Complexas Relações entre Cognição e Afeto. In: ARANTES, Valéria Amorim. Afetividade na Escola: alternativas teóricas e práticas. São Paulo: Summus Editorial, 2003.

SIERRA, Vânia Morales; MESQUITA, Wania Amélia. Vulnerabilidade e Fatores de Risco na Vida de Crianças e Adolescentes. São Paulo em Perspectiva, v. 20, n. 1, p. 148-155, jan./mar. 2006

SOARES, Magda Becker. Alfabetização e Letramento. São Paulo: Contexto, 2004. SOARES, Magda Becker. Letramento: um tema em três gêneros. Belo Horizonte: Autêntica, 1998.

SOUZA, Juliana Simões Zink. O Papel da Família na Constituição do Leitor. In: LEITE, Sérgio Antonio da Silva (Org.). Afetividade e Práticas Pedagógicas. São Paulo: Casa do Psicólogo, 2006. P. 223-252.

TAGLIAFERRO, Ariane Roberta. Meu Professor Inesquecível: a construção de uma memória coletiva. 2003. 78 f. Trabalho de Conclusão de Curso para Graduação em Pedagogia, Faculdade de Educação da Unicamp, Campinas, 2003.

TASSONI, Elvira Cristina Martins. A Afetividade e o Processo de Apropriação da Linguagem Escrita. In: LEITE, Sérgio Antonio da Silva (Org.). Alfabetização e Letramento: contribuições para as práticas pedagógicas. Campinas: Komedi, 2003. P. 223-259.

TASSONI, Elvira Cristina Martins. Afetividade e Aprendizagem: a relação professor-aluno. Campinas, 2000. Disponível em: <http://www.puc-campinas. edu.br/cca/producao/arquivos/extensao/Afetividade_aprendizagem.PDF $>$. Acesso em: 01 nov. 2011.

VYGOTSKY, Lev Semenovitch. A Formação Social da Mente: o desenvolvimento dos processos psicológicos superiores. São Paulo: Martins Fontes, 2007.

VYGOTSKY, Lev Semenovitch. Pensamento e Linguagem. São Paulo: Martins Fontes, 1987.

WALLON, Henri. A Evolução Psicológica da Criança. Lisboa, Portugal: Edições 70, 1995

WALLON, Henri. Psicologia da Educação e da Infância. Lisboa, Portugal: Editorial Estampa, 1975. 
Maria Isabel Donnabella Magrin é pedagoga com especialização em psicopedagogia. Mestre em Educação pela Universidade Estadual de Campinas. Professora atuante no ensino público há oito anos. Membro do grupo de pesquisa ALLE - Alfabetização, Leitura e Escrita, onde tem pesquisado sobre Alfabetização, Letramento e Afetividade nas práticas pedagógicas.

E-mail: bebel_vm@hotmail.com

Sérgio Antonio da Silva Leite é psicólogo. Doutor em Psicologia pela USP. Professor Titular da Faculdade de Educação da Unicamp. Membro do grupo de pesquisa ALLE. Autor de Alfabetização e Letramento (Summus Editora, 2011) e organizador de Afetividade e Práticas Pedagógicas (Caso do Psicólogo, 2006) e Afetividade e Letramento na Educação de Jovens e Adultos (Cortez Editora, 2013.)

E-mail: sasleite@uol.com.br 